University of Wollongong

Research Online

Faculty of Engineering and Information

Faculty of Engineering and Information

Sciences - Papers: Part B

Sciences

2019

\title{
A novel empirical heat transfer model for a solar thermal storage process using phase change materials
}

\author{
Yu Bie \\ Yunnan Normal Universiry, Kunming University of Science and Technology \\ Ming Li \\ Yunnan Normal Universiry \\ Fei Chen \\ Kunming University of Science and Technology \\ Grzegorz Krolczyk \\ Opole University of Technology \\ Lin Yang \\ Yunnan Normal Universiry
}

See next page for additional authors

Follow this and additional works at: https://ro.uow.edu.au/eispapers1

Part of the Engineering Commons, and the Science and Technology Studies Commons

Research Online is the open access institutional repository for the University of Wollongong. For further information contact the UOW Library: research-pubs@uow.edu.au 


\title{
A novel empirical heat transfer model for a solar thermal storage process using phase change materials
}

\begin{abstract}
Numerical and experimental analyses are often used to evaluate the solar thermal system with latent heat thermal energy storage (LHTES). However, the relationship between the numerical simulation and actual heat transfer process is still unclear. This work compares the simulated average temperature of two different phase change materials (PCMs) with experimental result at different operation conditions for the purpose of developing a temperature correction model. A novel empirical heat transfer model is then established to improve the simulation accuracy of PCM-based solar thermal systems. The contributions of this work include that (1) the system performance could be evaluated by the proposed empirical heat transfer model under sunny and cloudy weather conditions; (2) two PCMs (i.e., PCM1 and PMC2) are used to evaluate the performance of the proposed empirical heat transfer model. The analysis results demonstrate that (a) during solar irradiation variations, the temperature of the latent heat storage tank is much more stable than that of the sensible heat storage tank; $(b)$ the heat transfer power and heat storage amount of PCM1 per unit mass are less than that of the heat transfer oil, while the observations on PCM2 are as opposed to these obtained from PCM1; (c) there is a critical time/temperature for switching the operation mode of the heat storage between different weather conditions; (d) under the conditions of low temperature, low solar radiation intensity and short-time heat storage, LHTES may prefer to perform sensible heat storage rather than latent heat storage, and vice versa. The findings of this paper may provide a theoretical basis to determine the amount of the PCMs and the control strategy of operation model for LHTES.
\end{abstract}

\section{Keywords}

solar, novel, thermal, phase, change, materials, empirical, model, transfer, heat, process, storage

Disciplines

Engineering | Science and Technology Studies

\section{Publication Details}

Bie, Y., Li, M., Chen, F., Krolczyk, G., Yang, L., Li, Z. \& Li, W. (2019). A novel empirical heat transfer model for a solar thermal storage process using phase change materials. Energy, 168 222-234.

\section{Authors}

Yu Bie, Ming Li, Fei Chen, Grzegorz Krolczyk, Lin Yang, Zhixiong Li, and Weihua Li 


\title{
A Novel Empirical Heat Transfer Model for A Solar Thermal Storage Process using Phase Change Materials
}

\author{
Yu Bie ${ }^{1,2}$, Ming Li ${ }^{2, *}$, Fei Chen ${ }^{1}$, Grzegorz Królczyk ${ }^{3}$, Lin Yang ${ }^{2}$, Zhixiong Li ${ }^{4, *}$, Weihua $\mathrm{Li}^{4}$ \\ 1. Faculty of Chemical Engineering, Kunming University of Science and Technology, Kunming 650500, \\ China \\ 2. Solar Energy Research Institute, Yunnan Normal University, Kunming 650500, China \\ 3. Department of Manufacturing Engineering and Automation Products, Opole University of Technology, \\ Opole 45758, Poland \\ 4. School of Mechanical, Materials, Mechatronic and Biomedical Engineering, University of \\ Wollongong, Wollongong, New South Wales 2522, Australia \\ (email: bieyujuli@163.com; lmllldy@126.com; solarcf@163.com; grzegorz.krolczyk@wp.pl; \\ d394561585@163.com; zhixiong.li@ieee.org;weihuali@uow.edu.au)
}

\begin{abstract}
Numerical and experimental analyses are often used to evaluate the solar thermal system with latent heat thermal energy storage (LHTES). However, the relationship between the numerical simulation and actual heat transfer process is still unclear. This work compares the simulated average temperature of two different phase change materials (PCMs) with experimental result at different operation conditions for the purpose of developing a temperature correction model. A novel empirical heat transfer model is then established to improve the simulation accuracy of PCM-based solar thermal systems. The contributions of this work include that (1) the system performance could be evaluated by the proposed empirical heat transfer model under sunny and cloudy weather conditions; (2) two PCMs (i.e., PCM1 and PMC2) are used to evaluate the performance of the proposed empirical heat transfer model. The analysis results demonstrate that (a) during solar irradiation variations, the temperature of the latent heat storage tank is much more stable than that of the sensible heat storage tank; (b) the heat transfer power and heat storage amount of PCM1 per unit mass are less than that of the heat transfer oil, while the observations on PCM2 are as opposed to these obtained from PCM1; (c) there is a critical time/temperature for switching the operation mode of the heat storage between different weather conditions; (d) under the conditions of low temperature, low solar radiation intensity and short-time heat storage, LHTES may prefer to perform sensible heat storage rather than latent heat storage, and vice versa. The findings of this paper may provide a theoretical basis to determine the amount of the PCMs and the control strategy of operation model for LHTES.
\end{abstract}

\footnotetext{
* Corresponding author. Tel.: +86 87165517266.

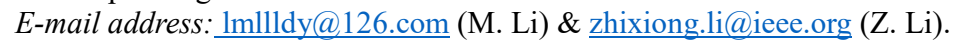


Keywords: Latent heat thermal energy storage; phase change materials; temperature correction; empirical heat transfer model

\section{Nomenclature}

$\mathrm{C}_{\mathrm{p}}$ constant-pressure specific heat capacity, $\mathrm{kJ} /(\mathrm{kg} \cdot \mathrm{K})$

$f \quad$ mass fraction of liquid phase

$h \quad$ specific enthalpy value, $\mathrm{kJ} / \mathrm{kg}$

$i \quad$ number of data collection

$L \quad$ latent heat, $\mathrm{kJ} / \mathrm{kg}$

$\dot{m} \quad$ mass flow rate, $\mathrm{kg} / \mathrm{s}$

$q \quad$ quantity of heat transfer, $\mathrm{kJ}$

$\dot{q} \quad$ heat transfer rate, $\mathrm{W}$

$t \quad$ temperature, ${ }^{\circ} \mathrm{C}$

\section{Greek symbols}

$\rho \quad$ density, $\mathrm{kg} / \mathrm{m} 3$

$\mu \quad$ dynamic viscosity, $\mathrm{kg} /(\mathrm{m} \cdot \mathrm{s})$

$\tau \quad$ time, minute

$\lambda \quad$ thermal conductivity, $\mathrm{W} /(\mathrm{m} \cdot \mathrm{K})$

$\beta \quad$ thermal expansion coefficient, $\mathrm{K}^{-1}$

$\alpha_{0}, \alpha_{1}, \alpha_{2}, \alpha_{3}, \omega$ environmental parameters

$\omega_{0}, \omega_{1}, \omega_{2}, \omega_{3}, v \quad$ environmental parameters

\section{Subscript}

pcm1, pcm2 phase change material 1 , material 2 in, out inlet, outlet

col collecting

ave average

$m \quad$ melting

$S, C \quad$ sunny day, cloudy day

$0,1,2$ the initial and other two states

$f \quad$ working fluid

$P \quad$ pressure

loss the heat lost

\section{Abbreviation}

SIPH solar industrial process heating

PTC parabolic trough collector

TES thermal energy storage

HE heat exchanger

PCM phase change materials

LHTES latent heat thermal energy storage

SHTES sensible heat thermal energy storage

HTF heat transfer fluid

DNI direct normal irradiation

temp. temperature 


\section{Introduction}

In most countries nowadays, the energy consumption of heat load in industrial sector accounts for about $15 \%-30 \%$ of the total energy consumption [1]. In China, the energy consumed by industrial sector reaches to $70.4 \%$ of the national total energy consumption in 2017 , while $50 \%-70 \%$ of industrial energy consumption is in the type of heat load [2]. That is to say, the industrial heat load energy consumption accounts for more than $30 \%$ of the national total energy consumption in China [2]. In order to meet the energy demand of industrial sector while protecting environment, renewable energy sources such as solar thermal energy have attracted considerable attention. During fast development period of solar energy a vast majority of existing solar energy systems operate at a low heat utilization temperature (below $80^{\circ} \mathrm{C}$ ), such as heating for domestic buildings [3]. However, nowadays high-temperature solar thermal power generation has gradually become the mainstream and the solar thermal utilization temperature is often above $350^{\circ} \mathrm{C}$ [4-5]. For example, the operation temperature for food production process such as food sterilization, pasteurization, drying, printing, dyeing and cleaning is generally around $250^{\circ} \mathrm{C}$ [6], which is suitable for the application of solar energy. As a result, the solar industrial process heat (SIPH) becomes a new research tendency in solar thermal utilization [7]. For a reliable medium-temperature solar thermal system, there are usually several indicators that need to consider, such as technical performance, economics and environmental impact. Good technical performance is a key factor to ensure the feasibility of a SIPH system with a thermal storage unit. Good technical performance indexes include high heat storage density, high heat transfer power, compatibility among heat transfer medium, heat storage material and heat exchanger, and small heat loss [8]. However, the heat storage performance of solar energy is subject to stochastic influence caused by intermittent and unstable solar radiation. It is always a challenging task to obtain good technical performance for solar energy utilization system [9].

In order to investigate the technical performance of solar energy utilization systems, many methods have been developed [9]. These methods can be categorized into three groups, i.e. the physics-based group, the numerical model-based group and the experimental test-based group. The physics-based group builds the theoretical/mathematical models using the undergoing physic laws to describe the solar energy system behavior [10]. The material thermal properties, the heat collection properties and the solar radiation parameters have been used to analytically calculate the system performance parameters such as the heat transfer power, heat storage and heat loss. However, most of existing analytical models only consider single conduction or convection process. Basically, due to the melting and solidification of the PCMs, the heat storage involves a complex two-phase unsteady heat transfer process. Moreover, the solid-liquid phase interface moves nonlinearly. Therefore, the heat storage process is much more complicated than single conduction/convection process. It is often difficult or impossible to obtain accurate analytical solutions [10]. 
More specifically, accurate temperature distribution and mass fraction of liquid phase of the PCMs are very difficult to calculate through mathematical models [11]. To compensate the physics models, numerical simulation and experimental test have been applied to solar thermal storage analysis $[12,13]$.

Thanks to the effectiveness and costless of numerical simulations, numerical model-based methods such as finite element analysis (FEM) [14-16] have been widely used to solve practical problems. The boundary problems that are difficult to solve using mathematical models can be effectively addressed using numerical simulation models [17]. With rapid development of computer technology, advanced commercial computational fluid dynamics (CFD) software (e.g. ANSYS/Fluent and TRNSYS) has been proven effective and efficient for phase change thermal storage simulation. The use of commercial software for numerical simulation of heat storage structures analysis and optimization has become a research hotspot in this field. Yang et al. [18] conducted CFD simulation to study the role of annulus fins in shell-and-tube heat storage tanks. Pizzolato et al. [19] proposed an optimization method based on topology and CFD to simulate and analyze the natural convection in heat transfer enhancement in phase change heat storage tanks. For latent heat thermal energy storage (LHTES) simulation, Fornarelli et al. [20] carried out CFD analysis of the shell-and-tube phase change thermal storage device in a solar thermal power plant to compare the difference between a pure thermal model and a model with thermal convection. Dutil et al. [21] conducted a mathematical simulation of a LHTES system and found that numerical simulation is very useful for performing the nonlinear thermal performance analysis of LHTES systems. Furthermore, recent investigations focus on predicting the melting and solidification behavior of PCMs. Augspurger et al. [22] investigated the effect of combined metal fins for heat spreading and recovery with PCM (a mixture of NaNO3 and KNO3). Kastner et al. [23] investigated the aquifer thermal energy storage for saisonal solar thermal heat storage by means of transient subsurface FEM modeling. Bie et al. [24] used CFD simulation to analyze the heat storage and heat release performance of different PCMs in the melting and solidification process. Although simulated models can save time and cost for solar thermal system investigation, there are no standard rules to judge the correctness and reliability of the simulation results. It is necessary to correlate numerical analysis with experimental exploration to discuss and modify the simulation models.

Experimental test is involved with two aspects, one is to verify the validity of simulation calculations $[14,25,26]$ and the other is to directly explore the heat storage/release properties. There is usually a certain error between the simulated and the experimental results. Bayon et al. [27] studied the heat storage performance of a specific solar heat storage system for steam production. There was a quite large error between the simulated and the experimental results, while within a limited range the experimental result is in good agreement with the numerical result. Al-Jethelah et al. [28] developed a Nano-PCM filled energy storage system. The numerical simulation and experimental test were implemented to describe the internal 
melting process of the thermal storage system. However, there is still a big difference between the theoretical calculation and the experimental result. Lu et al. [29] developed a PCM floor coupled with solar water heating system for the storage of waste heat in buildings. The comparison between TRNSYS simulation and experiment showed good consistency with a variation range of $2-3^{\circ} \mathrm{C}$ in temperature. In order to explore the heat storage/release properties of PCMs, Yuan et al. [30] conducted experiments to evaluate three types of high temperature PCMs in different boundary conditions. Kabeel et al. [31] experimentally investigated the solar air heaters with/without PCM thermal storage. The results show that PCM thermal storage can improve the thermal storage efficiency significantly. Xue [32] investigated the effect of operating flow using different solar collectors and the effect of solar radiation intensity and ambient temperature on the solar heat storage performance. Motahar et al. [33] investigated the solidification process of a TiO2 nanoparticle based PCM. The solidified volume and temperature distribution were found to significantly influence the solidification. More recent progress on the PCM-enhanced thermal storage systems can be found in [34-36].

Although much work has been done to address the technical performance of solar energy utilization systems, literature review indicates that the relationship between the numerical simulation and actual heat transfer process is still unclear. This is because numerical simulations always assume certain thermal boundary conditions, which is not realistic in practice. In most cases the simulated boundary conditions cannot be verified in heat storage experiment tests. As a result, the simulation conditions do not form a corresponding relationship with the heat boundary in actual solar energy storage process. However, while the experimental tests are able to provide reliable results it is rather expensive and time-consuming to carry out these experiments. It is therefore crucial to establish the maps describing the relationship between the numerical simulations and experiments in order to modify the simulated models. Unfortunately, very limited work has been found to address this issue in literature.

In order to bridge the aforementioned research gap in modelling the PCM-based solar thermal storage process, a novel empirical heat transfer model is proposed in this paper. Firstly, a theoretical model was established by expressing the solar thermal storage process as a function of the heat source temperature and the operating time of the PCM melting process. Then simulation analysis and experiment tests were compared in the same/similar boundary conditions in order to obtain the relationship between the simulated and experimental heat source average temperatures. Based on the comparison result a temperature-bias correction model was developed to modify the theoretical model. A heat transfer model was thus obtained to better simulate the PCM melting process in the LHTES system.

\section{Basic theory of solar storage utilization system}




\subsection{Experimental platform}

The experiment platform used in this paper is based on the indirect heat-generating steam system of trough concentrating solar heat collector for phase change heat storage. The experimental platform consists of three subunits, i.e. one $36 \mathrm{~m}^{2}$ solar collector unit for heating the heat transfer fluid (HTF), one heat storage unit consisting of a 75 L SHTES tank and a 15 L LHTES tank, and one heat utilization unit for heating steam and hot water. These subunits are connected by pipelines, pumps and valves. The trough collector converts solar radiant energy into heat while HTF absorbs heat and stores energy directly or indirectly in the SHTES or LHTES. Then through the connection loop of the heat storage utilization units, the HTF and water in the LHTES tank exchange heat via a tube-shell heat exchanger, directly producing steam or hot water. The heat circuit can either operate simultaneously with the heat storage loop in the daytime, nor separately at night or in cloudy days. Fig. 1 shows a photo of the experimental platform, where several temperature and flow sensors are installed into the operating circuit. Temperature sensors are arranged in the phase change heat storage tank to measure the temperatures and flow rates at different positions. In addition, direct radiometers and anemometers are also used to obtain real-time measurements of the solar radiation intensity and environment parameters. In order to explore the characteristics of the phase change heat storage, six temperature probes are installed from point A to F in the LHTES tank (see Fig. 1). The data is recorded by a paperless recorder, and the sample frequency is $60 \mathrm{~Hz}$.

The schematic structure of the experiment platform is shown in Fig. 2. This solar-driven experiment system can test a variety of operation modes through valve adjustment but only two modes are involved with heat storage, i.e. one is solar collecting with thermal energy storage (TES) and the other is solar collecting with TES and heat utilization, all in daytime. Because this paper does not target at keeping a stable heat output, the assisted heat source, which is significant for a real industry production, is not considered in the experimental test. The experiments conducted in this paper are mainly in the solar fieldLHTES-oil tank-solar field cycle, as shown in the blue cycle route in Fig. 2. In the condition of strong solar radiation, the thermal utilization unit starts to work in order to manage the temperature limit in the circuit, as shown in the red cycle route in Fig. 2. The detailed operation modes of the experimental tests are listed in Table 1. It can be seen that some valves (such as $\mathrm{V}_{2}$ and $\mathrm{V}_{3}$ ) do not appear in the route, but they are also very useful to keep the HTF running in other routes. 


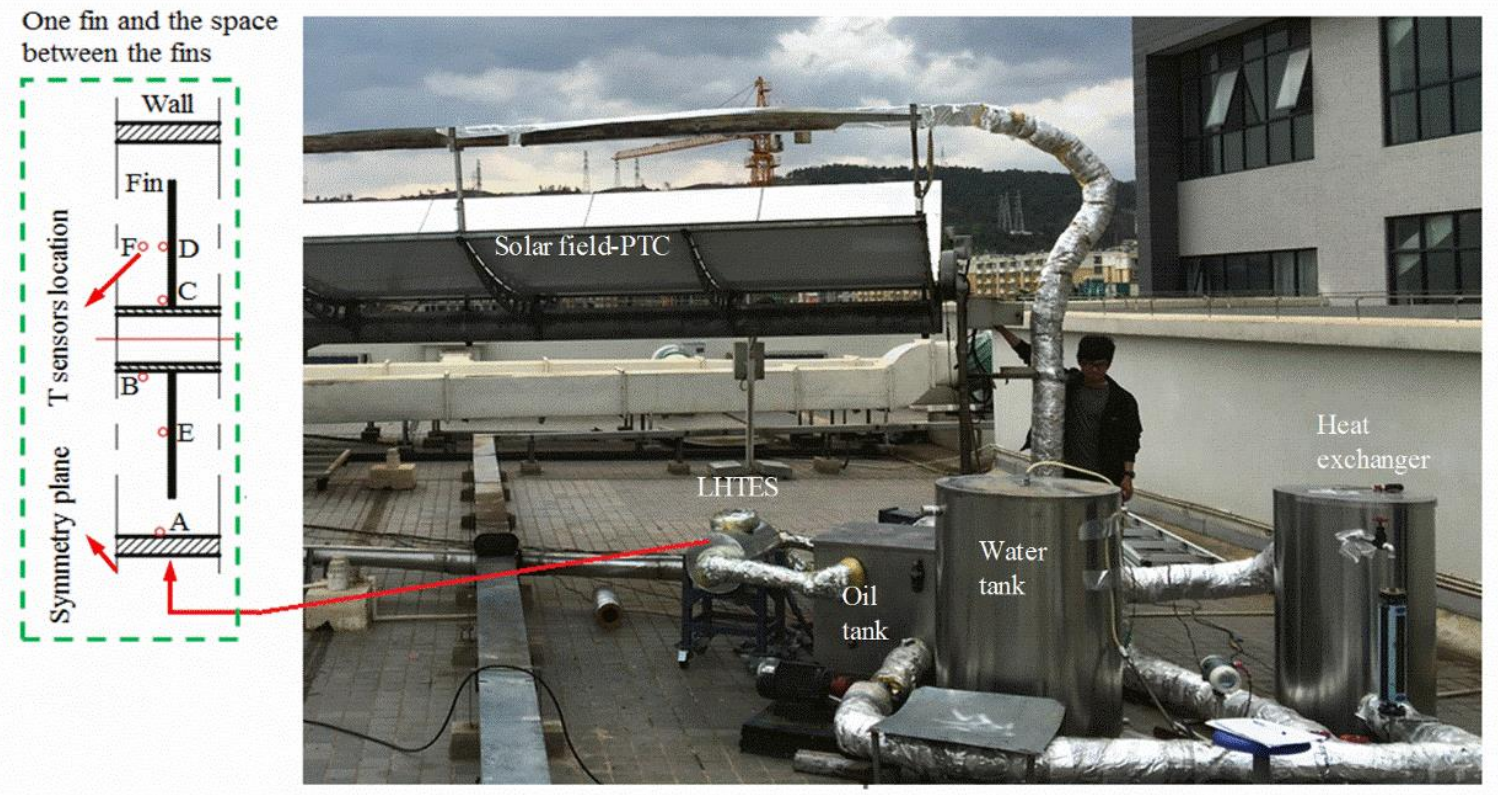

Fig. 1. Specially-designed experimental platform for PCM solar thermal storage.

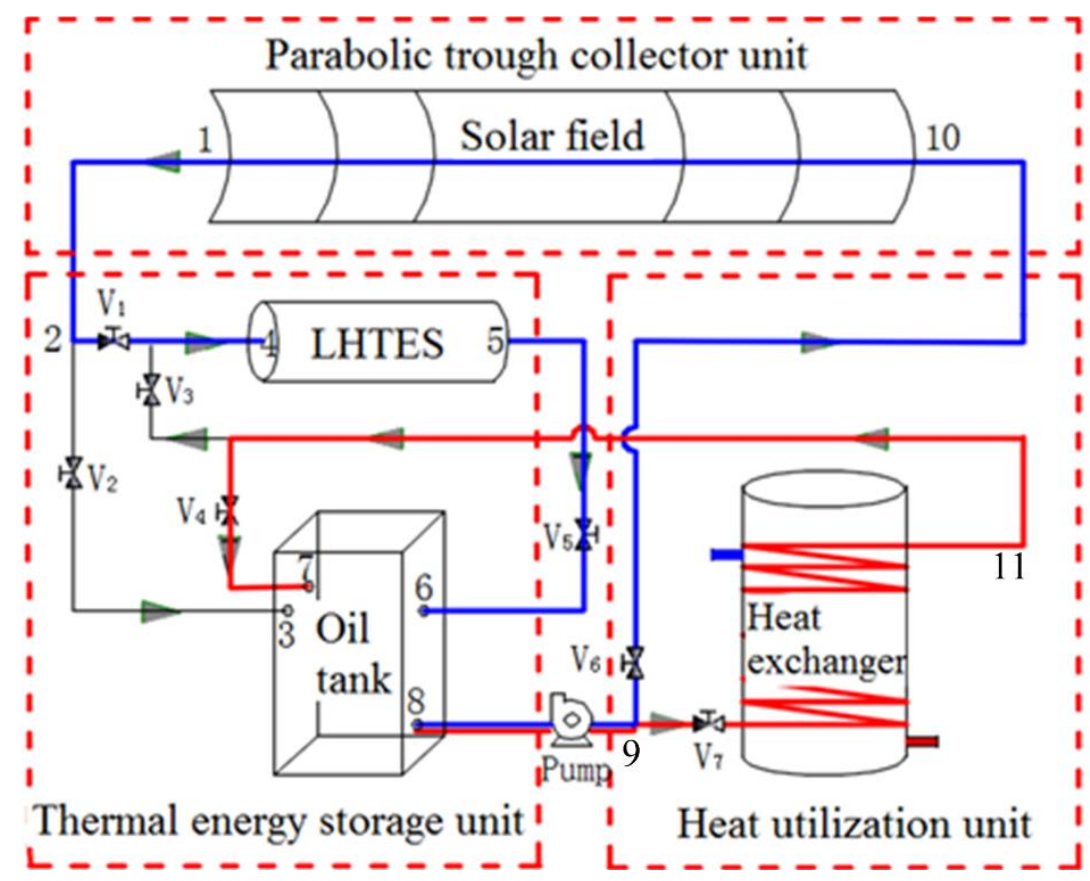

Fig. 2. Schematic structure of experimental platform of solar storage utilization system.

Table 1. System operation modes in typical weather conditions.

Weather Operation mode $\quad$ PTC unit TES unit HE unit HTF circulation loop




\begin{tabular}{|c|c|c|c|c|c|}
\hline Cloudy & $\begin{array}{l}\text { Solar collecting }+ \\
\text { TES at day time }\end{array}$ & Run & $\begin{array}{l}\text { SHTES+ } \\
\text { LHTES }\end{array}$ & Close & $\begin{array}{l}1-2-\mathrm{V}_{1}-4-5-\mathrm{V}_{5}-6-8-9-\mathrm{V}_{6}- \\
10-1(\mathrm{TES} \text { loop in blue) }\end{array}$ \\
\hline Sunny & $\begin{array}{l}\text { Solar collecting }+ \\
\text { TES + Heat } \\
\text { utilization at day time }\end{array}$ & Run & $\begin{array}{l}\text { SHTES+ } \\
\text { LHTES }\end{array}$ & Run & $\begin{array}{l}1-2-\mathrm{V}_{1}-4-5-\mathrm{V}_{5}-6-8-9-\mathrm{V}_{6}- \\
10-1 ;(\mathrm{TES} \text { loop in blue) } \\
8-9-\mathrm{V}_{7}-11-\mathrm{V}_{4}-7-8(\mathrm{HE} \\
\text { loop in red) }\end{array}$ \\
\hline
\end{tabular}

\subsection{Mathematical TES model}

The mathematical and physical models of the LHTES and SHTES are shown in Fig. 3.

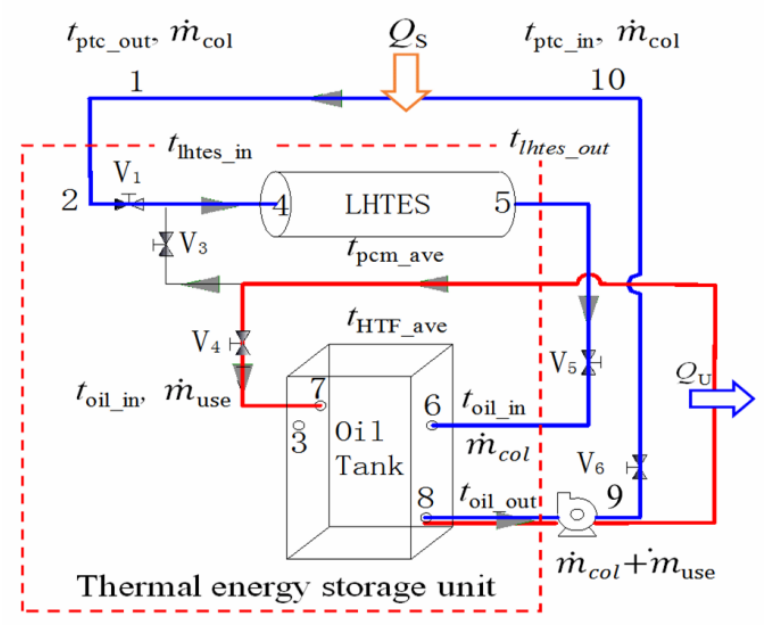

Fig. 3. Mathematical and physical model of TES unit.

The sensible heat storage power of the heat storage tank at the $i$-th minutes is

$$
\dot{Q}_{\text {SHTES }}(i)=\left(\dot{m}_{\mathrm{col}}+\dot{m}_{\mathrm{use}}\right) \cdot C_{\mathrm{P} \_ \text {htf }}(i)\left(t_{\mathrm{htf} \_a v e}(i)-t_{\mathrm{htf} \_a v e}(i-1)\right) / 60
$$

The heat storage/exothermic power of unit mass HTF at the $i$-th minute and the cumulative heat storage/release heat at the end of the time are calculated by the following two equations.

$$
\begin{aligned}
\dot{q}_{\text {SHTES }}(i) & =C_{\mathrm{P} \_ \text {htf }}(i)\left(t_{\mathrm{htf} \_a v e}(i)-t_{\mathrm{htf} \_a v e}(i-1)\right) / 60 \\
q_{\text {SHTES }} & =\sum_{i=1}^{\text {endtime }} C_{\mathrm{P} \_\mathrm{htf}}(i)\left(t_{\mathrm{htf} \_ \text {ave }}(i)-t_{\mathrm{htf} \_ \text {ave }}(i-1)\right)
\end{aligned}
$$


The thermal power storage/release at the $i$-th minute and accumulated thermal power storage/release of the LHTES for unit mass are defined by the following equations.

$$
\begin{aligned}
& \dot{q}_{\text {LHTES }}(i)=\left[C_{\mathrm{P} \_ \text {pcm }}(i)\left(t_{\mathrm{pcm} \_ \text {ave }}(i)-t_{\mathrm{pcm} \_\mathrm{ave}}(i-1)+(f(i)-f(i-1)) \cdot L\right] / 60\right. \\
& q_{\mathrm{LHTES}}=\sum_{i=1}^{\text {endtime }} C_{\mathrm{P} \_\mathrm{pcm}}(i)\left(t_{\mathrm{pcm} \_ \text {ave }}(i)-t_{\mathrm{pcm} \_ \text {ave }}(i-1)+(f(i)-f(i-1)) \cdot L\right.
\end{aligned}
$$

where, $\dot{Q}(i)$ is stored/released thermal power at the $i$-th minutes, $\dot{q}(i)$ is that of the unit mass HTF, and the power is equal to accumulated quantity in one minute divided by 60 seconds, and $q$ is the accumulated thermal power for the whole process. As can be known from Eqs. (1-5) that the calculation of the heat transfer power and the heat transfer amount in the sensible heat transfer process involves only a change in temperature and is easy to measure. The average temperature of the PCM can be measured experimentally or calculated from numerical simulations. However, the mass fraction of liquid phase at every minute cannot be directly measured. Numerical simulation is one of the effective methods to calculate both the average temperature and the mass fraction of liquid phase of the PCM.

\section{Numerical simulations}

\subsection{Selection of phase change materials}

The purpose of numerical simulations is to calculate theoretical TES results and provide a theoretical basis for establishing empirical heat transfer models. The objects of the numerical simulations are the melting and heat storage process of two types of PCMs. PCM1 is a binary nitric acid molten salt phase change heat storage material $\left(50 \mathrm{wt} \% \mathrm{NaNO}_{3}-50 \mathrm{wt} \% \mathrm{KNO}_{3}\right)$ for the subsequent experiment process, and PCM2 is formed by adding an additive into the Hitec (40 wt $\% \mathrm{NaNO}_{2}-7 \mathrm{wt} \% \mathrm{NaNO}_{3}-53 \mathrm{wt} \% \mathrm{KNO}_{3}$ ), which is a commonly used ternary nitric acid molten salt in high temperature range. The thermal properties of these two materials are shown in Table 2, including the density $\rho\left(\mathrm{kg} / \mathrm{m}^{3}\right)$, heat transition temperature $t_{m}$ $\left({ }^{\circ} \mathrm{C}\right)$, latent heat $L(\mathrm{~kJ} / \mathrm{kg})$, thermal conductivity $\lambda[\mathrm{W} /(\mathrm{m} \cdot \mathrm{K})]$, constant-pressure specific heat capacity $C_{P}$ $(\mathrm{kJ} / \mathrm{kg} \cdot \mathrm{K})$, dynamic viscosity $\mu[\mathrm{kg} /(\mathrm{m} \cdot \mathrm{s})]$, and thermal expansion coefficient $\beta\left(\mathrm{K}^{-1}\right)$.

The PCM properties determine the thermal storage performance of the solar thermal storage system. Since PCM1 and PCM2 belong to the same type of molten salt, their overall heat transfer characteristics trends are consistent except some local differences. Because the thermal conductivities of these two PCMs are quite different, it is convenient not only to highlight the differences of their LHTES performance with respect to the phase transition temperature and latent heat rate, but also to compare with their SHTES performance. 
Table 2. Thermophysical properties of molten salt PCMs.

\begin{tabular}{|c|c|c|c|c|}
\hline Parameters & \multicolumn{2}{|c|}{ PCM1 [24] } & \multicolumn{2}{|c|}{ PCM2 [37] } \\
\hline \multirow{2}{*}{$\rho\left(\mathrm{kg} / \mathrm{m}^{3}\right)$} & Solid state & 2079.0 & Solid state & 2130 \\
\hline & Liquid state & 1884.0 & Liquid state & 2081.2 \\
\hline \multirow{2}{*}{$t_{m}\left({ }^{\circ} \mathrm{C}\right)$} & Melting & $218 \sim 228$ & Melting & $137 \sim 140$ \\
\hline & Solidification & $215 \sim 225$ & Solidification & $140 \sim 143$ \\
\hline$L(\mathrm{~kJ} / \mathrm{kg})$ & \multicolumn{2}{|c|}{122.89} & \multicolumn{2}{|c|}{52.3} \\
\hline \multirow{3}{*}{$\lambda(\mathrm{W} /(\mathrm{m} \cdot \mathrm{K}))$} & Solid state & 0.705 & \multirow{3}{*}{\multicolumn{2}{|c|}{$\begin{array}{c}1.3\left(\mathrm{~T} \leq 100^{\circ} \mathrm{C}\right) \\
2.0484\left(100^{\circ} \mathrm{C}<\mathrm{T} \leq 150^{\circ} \mathrm{C}\right) \\
1.4289\left(\mathrm{~T}>150^{\circ} \mathrm{C}\right)\end{array}$}} \\
\hline & \multirow{2}{*}{ Liquid state } & \multirow{2}{*}{0.478} & & \\
\hline & & & & \\
\hline \multirow[b]{2}{*}{$C_{P}(\mathrm{~kJ} / \mathrm{kg} \cdot \mathrm{K})$} & \multicolumn{2}{|c|}{$1.05\left(\mathrm{~T} \leq 90^{\circ} \mathrm{C}\right)$} & \multicolumn{2}{|c|}{$2.13\left(\mathrm{~T} \leq 90^{\circ} \mathrm{C}\right)$} \\
\hline & \multicolumn{2}{|c|}{$\begin{array}{c}1.85\left(90^{\circ} \mathrm{C}<\mathrm{T} \leq 228^{\circ} \mathrm{C}\right) \\
1.50\left(\mathrm{~T}>228^{\circ} \mathrm{C}\right)\end{array}$} & \multirow{2}{*}{\multicolumn{2}{|c|}{$\begin{array}{c}3.89\left(90^{\circ} \mathrm{C}<\mathrm{T} \leq 228^{\circ} \mathrm{C}\right) \\
2.50\left(\mathrm{~T}>228^{\circ} \mathrm{C}\right) \\
0.00301\end{array}$}} \\
\hline$\mu(\mathrm{kg} /(\mathrm{m} \cdot \mathrm{s}))$ & 0.0 & & & \\
\hline \multirow{2}{*}{$\beta\left(\mathrm{K}^{-1}\right)$} & Melting & $5.47 \times 10^{-5}$ & Melting & $2.6 \times 10^{-4}$ \\
\hline & Solidification & $7.06 \times 10^{-5}$ & Solidification & $9.7 \times 10^{-6}$ \\
\hline
\end{tabular}

\subsection{The numerical simulation results of temperature and mass fraction of the liquid phase}

After selecting the PCMs, the numerical simulation model is established for the specific structure of the LHTES tank. The boundary condition and calculation setting are listed in Appendix A. The simulation results are validated by experimental tests [24]. It is worth mentioning that the accuracy of the temperature distribution is assessed using the average temperature of the heat storage tank. Based on error analysis and reliability verification, the measured value of point A (see Fig. 1) is discarded due to large error, only the average temperatures from point $\mathrm{B}$ to point $\mathrm{F}$ are selected to calculate the average temperature of the PCMs. It is realistic to describe the temperature distribution inside the LHTES tank using average temperature.

According to different heat source boundary temperatures, the simulated temperature and the mass fraction of liquid phase of the PCMs in the LHTES can be obtained, as shown in Fig. 4. 


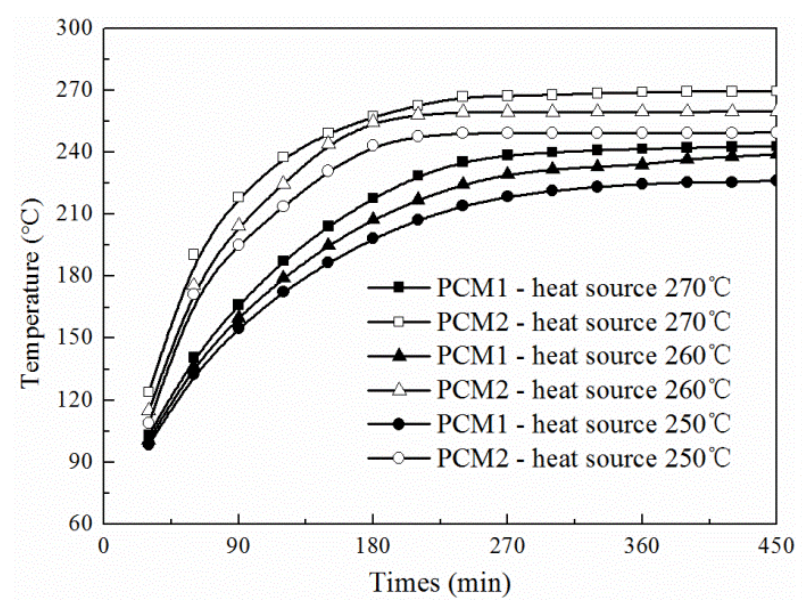

(a) Simulated temperature

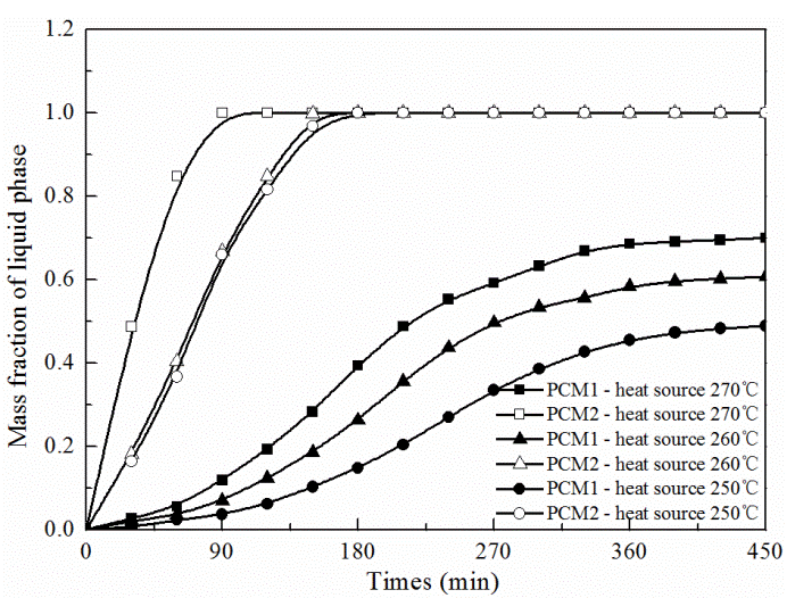

(b) Simulated mass fraction of liquid phase

Fig. 4. Simulation results of the two PCMs.

As can be seen in Fig. 4 (a), the PCMs exhibit different heat transfer characteristics due to different material properties. The temperature rise of the PCM2 is obvious, and in stabilization stage its average temperature is larger than that of the PCM1 in different heat source temperature conditions. However, the basic heat transfer law of the PCMs is the same; that is, as the heat transfer process continues, the average temperature of the PCMs rapidly rises at the beginning and then gradually slows down. The average temperature of the PCMs mainly corresponds to the temperature of the heat source and the time of the melting process.

As can be seen in Fig. 4 (b), the mass fraction of liquid phase of both PCMs is influenced by the influence of heat source temperature. The mass fraction of liquid phase of PCM2 reaches the value of 1 in a relatively short period of time while PCM1 remains in the lower range within limited solar irradiation duration. The reason for this behavior is because of the thermo-physical properties differences between PCM1 and PCM2.

Based on the theoretical calculation results in Fig. 4, the relationship among average temperature, mass fraction of liquid phase, heat source temperature and melting duration in the LHTES tank is obtained. The results are shown in Figs. 5 and 6. In Fig. 5 the fitting plane is obtained to describe the relationship. Due to the relationship between the heat source temperature and the calculated temperature, the theoretical calculation area is the area on the right side of the dividing line. Based on the fitting results of the average temperature, the fitting plane for the mass fraction of liquid is obtained (see Fig. 6). 


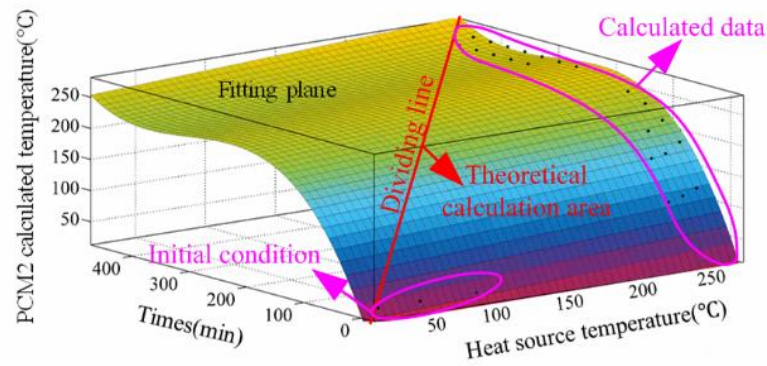

(a) PCM1

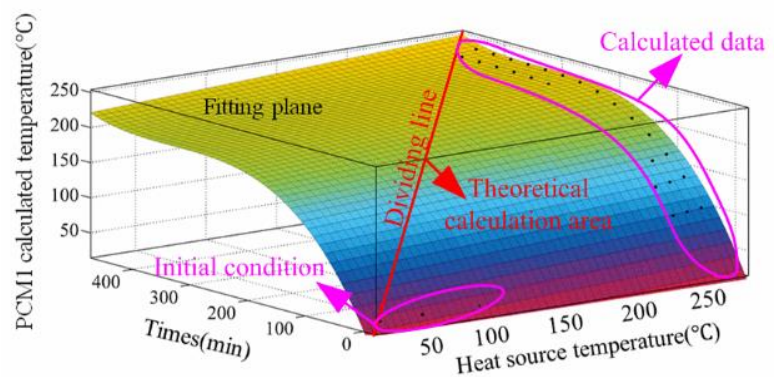

(b) PCM2

Fig. 5. Fitting results of average temperature.

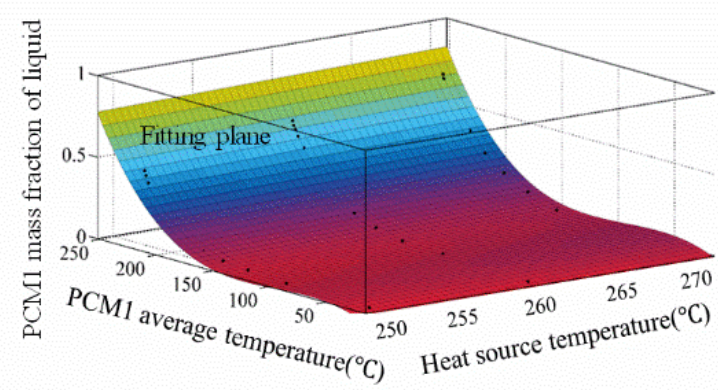

(a) PCM1

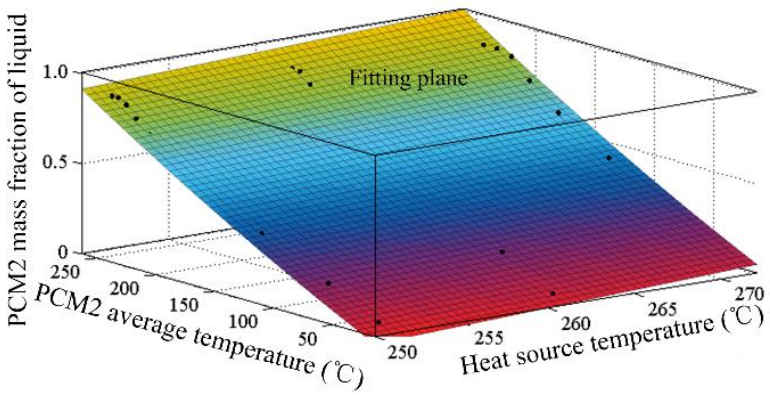

(b) PCM2

Fig. 6. Fitting results of mass fraction of liquid phase.

By analyzing the fitting results, the average PCM temperature shows a polynomial relationship with the time and temperature of the heat source, and the mass fraction of liquid phase is expressed as a polynomial relationship between the heat source temperature and the PCM temperature, as shown in Eqs. (6-9). The average temperature fitting function for PCM1 can be expressed as (R-square $=0.9851)$ :

$$
t_{\text {pcm1_ave }}=15.47+5.293 \times 10^{-6} \tau^{3}-0.005227 \tau^{2}+1.719 \tau+0.1008 t_{\text {lhtes_in }}
$$

The average temperature fitting function for PCM2 can be expressed as (R-square=0.9813):

$$
t_{\text {pcm2_ave }}=13.9+9.337 \times 10^{-6} \tau^{3}-0.008426 \tau^{2}+2.399 \tau+0.1181 t_{\text {lhtes_in }}
$$

The mass fraction of liquid phase fitting function for PCM1 can be expressed as (R-square=0.9892):

$$
f_{P C M 1}=-0.6097+1.965 \times 10^{-3} t_{\text {lhtes_in }}+5.005 \times 10^{-3} t_{\text {pcm1_ave }}-5.97 \times 10^{-5} t_{\text {pcml_ave }}{ }^{2}+2.14 \times 10^{-7} t_{\text {pcm1_ave }}^{3}
$$

The mass fraction of liquid phase fitting function for PCM2 can be expressed as (R-square=0.9830):

$$
f_{P C M 2}=-1.305+0.004735 t_{\text {lhtes_in }}+2.865 \times 10^{-3} t_{\text {pcm2_ave }}+1.086 \times 10^{-5} t_{\text {pcm2_ave }}{ }^{2}-1.859 \times 10^{-8} t_{\text {pcm2_ave }}{ }^{3}
$$


where $t_{\mathrm{pcm} 1 \_a v e}$ is average temperature of PCM1 $\left({ }^{\circ} \mathrm{C}\right), t_{\mathrm{pcm} 2 \_a v e}$ is average temperature of PCM2 $\left({ }^{\circ} \mathrm{C}\right)$, $t_{\mathrm{pcm} 1}, f_{\mathrm{pcm} 2}$ are the mass fraction of liquid phase of PCM1 and PCM2, $\tau$ is the real time of the melting process, and $t_{\text {lhtes_in }}$ is the heat source temperature of the tank inlet, respectively.

From Eqs. (6-9) it can be observed that the average temperature and mass fraction of liquid phase of the PCMs are influenced by the heat transfer characteristics. For example, the PCM average temperature maintains a linear relationship with the temperature of the heat source. The mass fraction of liquid phase maintains a complex polynomial relationship with the heat source temperature and heat transfer time. The heat source temperature is affected by the operating time of the solar energy utilization system, solar radiation intensity and environmental factors. Therefore, a universal expression for the average temperature to PCM liquid phase ratio can be determined by

$$
\begin{aligned}
& t_{\mathrm{pcm} \_a v e}=\alpha_{0}+\alpha_{1} \tau+\alpha_{2} \tau^{2}+\alpha_{3} \tau^{3}+\beta t_{\text {lhtes_in }} \\
& f=\omega_{0}+\omega_{1} t_{\mathrm{pcm} \_ \text {ave }}+\omega_{2} t_{\mathrm{pcm} \_a v e}{ }^{2}+\omega_{3} t_{\text {pcm_ave }}{ }^{3}+v t_{\text {lhtes_in }}
\end{aligned}
$$

where $\alpha_{0}, \alpha_{1}, \alpha_{2}, \alpha_{3}, \beta$ are defined as the environmental parameters and $\omega_{0}, \omega_{1}, \omega_{2}, \omega_{3}, v$ are calculated from $\alpha_{0}, \alpha_{1}, \alpha_{2}, \alpha_{3}, \beta$

\section{Experimental analyses}

The main purpose of the experimental test is to establish an empirical heat transfer model based on the comparison between numerical simulations and experiments. Since the relationship among the average temperature, the mass fraction of liquid phase, the heat source temperature, and the melting time has been obtained, the experimental tests in actual weather conditions are carried out to verify the established relationship. Through the experiments, actual temperature in the LHTES tank is measured to build the bias correction model for the simulation model.

\subsection{The characteristics of collector inlet and outlet temperatures}

In this paper, the measured data in two typical weather conditions (cloudy day and sunny day) are selected for analysis. Fig. 7 provides the solar radiation intensity, where the solar radiation power is strongly affected by the clouds. Under cloudy weather condition, the solar radiation power is continuously fluctuating. The direct normal irradiation (DNI) rose to the level at which it could be collected at 11:42 am, and dropped to almost zero at 14:41 pm. Only the 25 min collection of heat and heat stored from 11:42 was tested. In sunny days, under normal sunlight conditions, the power is kept at a relatively high value. Before 
the sunset, its radiation intensity starts to fluctuate until 0 at the sunset. The measuring instrument records the heat collection within 445 minutes from 9:50 am.

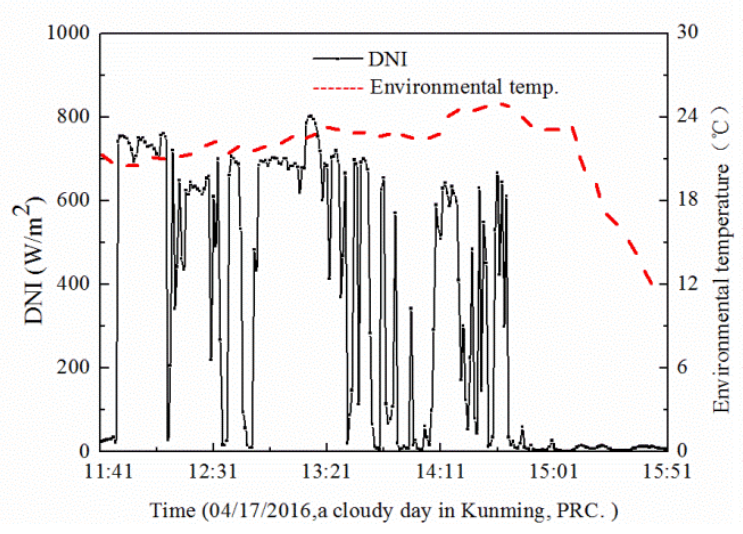

(a) Cloudy day

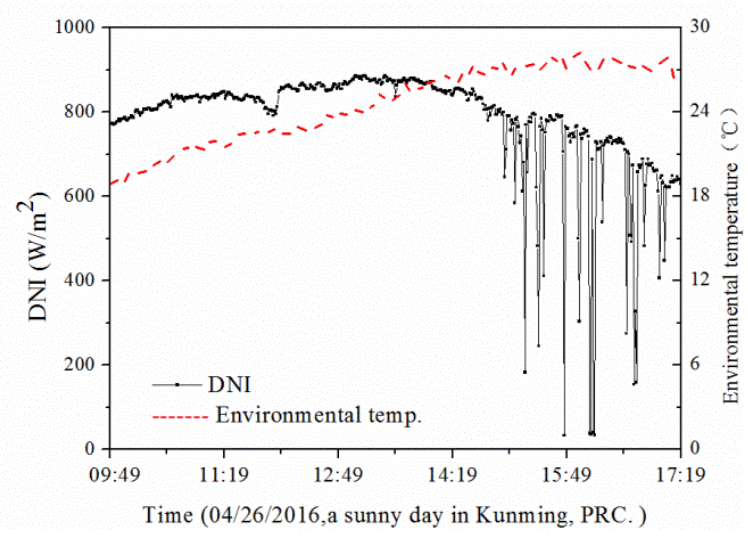

(b) Sunny day

Fig. 7. The experimental conditions for the LHTES test.

The inlet and outlet temperatures of a trough collector are shown in Fig. 8. In cloudy days, the maximum temperature in the oil circuit is about $190^{\circ} \mathrm{C}$ in the normal operating temperature range of the experimental platform. In sunny days, the outlet temperature of the collector reaches to $240^{\circ} \mathrm{C}$ after twohour normal operation. When the oil temperature reaches to $270^{\circ} \mathrm{C}$ for quite a long time, it may cause the HTF degradation and decrease the heat transfer efficiency. In addition, it may damage the experiment equipment if the pipeline temperature is too high. The HTF exchanges the thermal energy with the cold water to produce low-pressure vapor. In the experiments, the temperature of vapor can reach to $126^{\circ} \mathrm{C}$ in a sunny day. The power can be adjusted by changing the solar collector area. In this paper, the HTF flow is controlled manually when HTF temperature at the PTC outlet is over $240^{\circ} \mathrm{C}$. Different loads are switched by adjusting the valves to make sure the HTF flow $\dot{m}_{c o l}$ for heat storage and the HTF flow $\dot{m}_{u s e}$ for heat utilization are in different proportions of 1:1,2:1 and 1:2, respectively. 


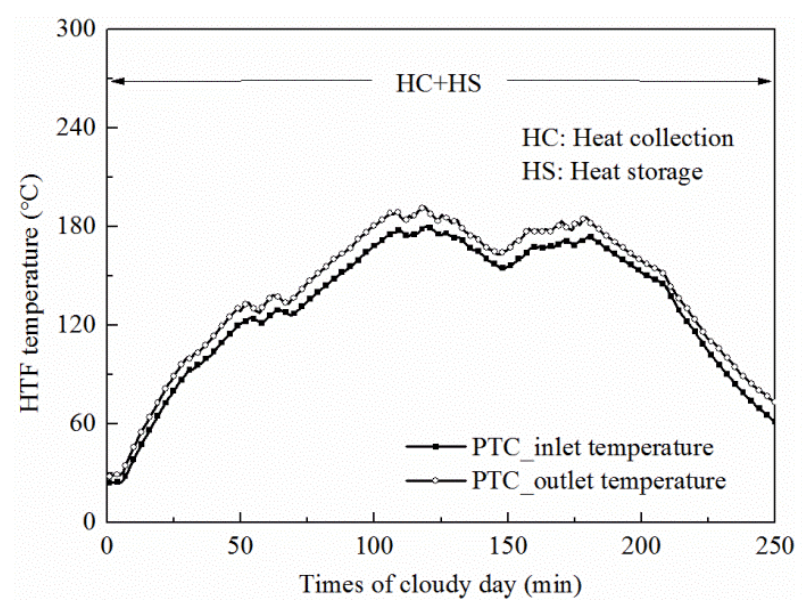

(a) Cloudy day

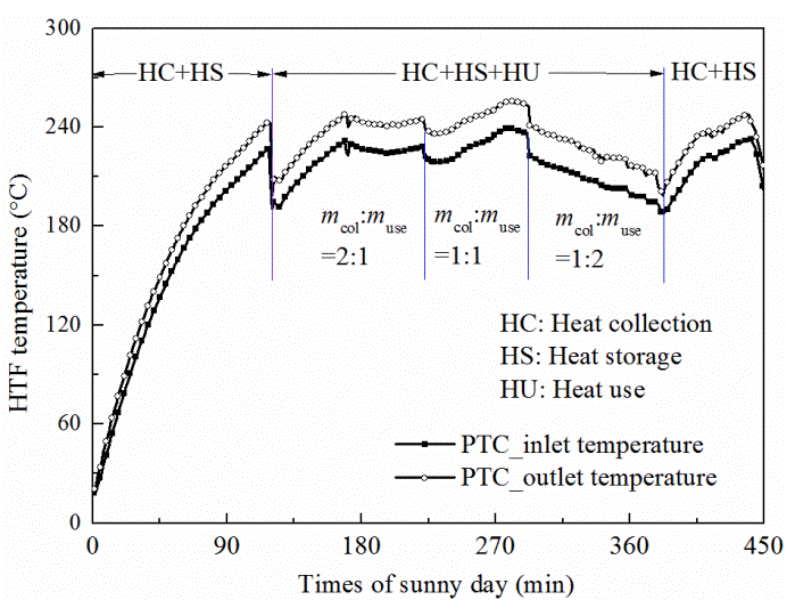

(b) Sunny day

Fig. 8. Experimental results of the HTF temperature.

\subsection{Internal temperature distribution and average temperature in the LHTES}

During the test, the temperature data in the LHTES tank has been tested. The temperature distribution and the average temperature in the tank under typical weather conditions are described in Fig. 9. The temperature distributions of the inlet and outlet of the tank are almost the same in Fig. 9. This is because the temperature loss in the pipe and the heat collection chamber is very little. The difference between the LHTES inlet and outlet temperatures is not higher than $1{ }^{\circ} \mathrm{C}$, which is related to the slow heat transfer of phase change heat storage. In the LHTES tank with six points setting inside, the temperature difference is large, the internal temperature stratification is obvious, and pear-shaped distribution is observed. The temperatures at points B and C which close to the HTF pipe are the highest, and the upper point of the symmetrical position is higher than the lower point, which is related to the thermal convection caused by the density difference. In addition, point $\mathrm{A}$ is at the bottom of the tank and near the periphery, therefore its temperature maintains the same variation trend and the value is relatively lower. This is because point $\mathrm{A}$ is close to the outer wall with an unsatisfactory thermal insulation effect. This is consistent with the description in the Appendix A. Therefore, the average temperature result is a weighted average of points B-F. 


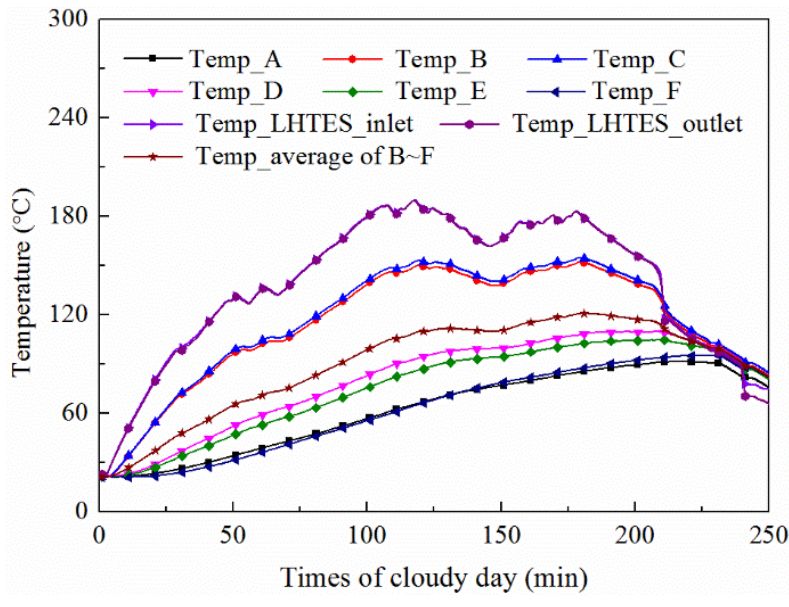

(a) Cloudy day

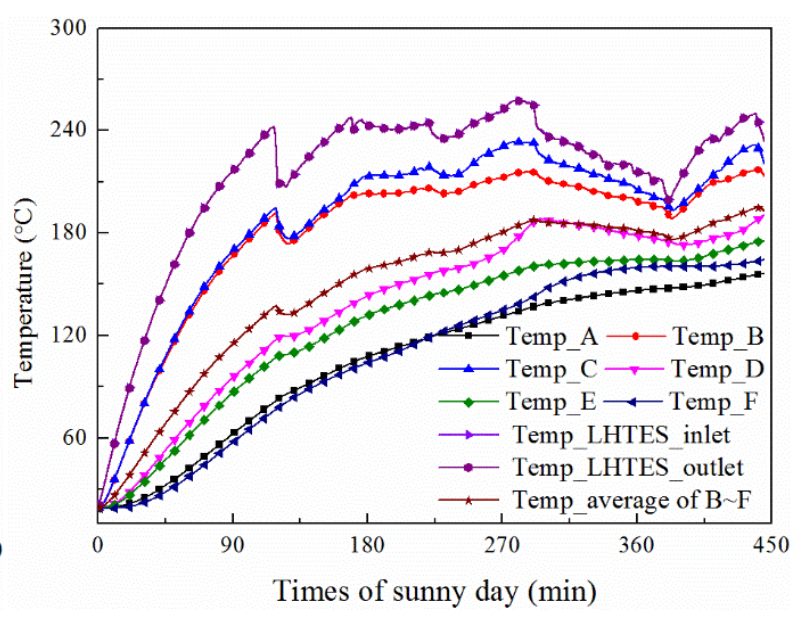

(b) Sunny day

Fig. 9. Measured temperature distribution of HTF and PCM in LHTES.

\subsection{Temperature correction model for LHTES charging process}

A temperature bias correction model between measured and simulated data is established. Fig. 10 depicts the temperature correction results for PCM1 and PCM2 in different weather conditions.

The fitting functions for correcting the temperature in sunny and cloudy days are expressed in Eqs. (12) and (13), respectively. The temperature bias correction can be expressed as a function of time and theoretical temperature. Eqs. (12) and (13) are similar; the only different is the coefficients. This is because under different weather and environmental conditions, the heat loss in the LHTES tank is greatly affected by the ambient temperature and wind speed.

$$
\begin{gathered}
t_{s, \text { corrected }}=3.462-0.1291 \tau+0.674 t_{\text {calculated }} \\
t_{\text {c,corrected }}=-0.221-0.064 \tau+0.703 t_{\text {calculated }}
\end{gathered}
$$

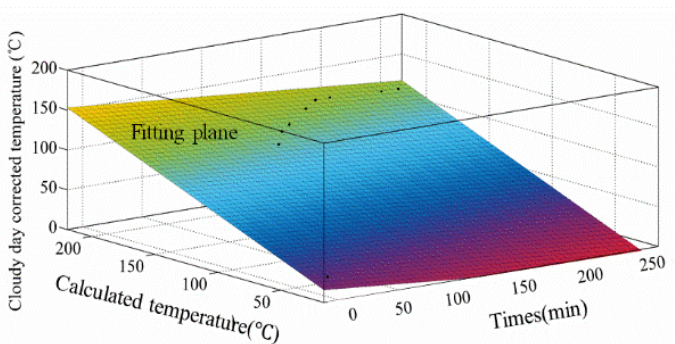

(a) Cloudy day

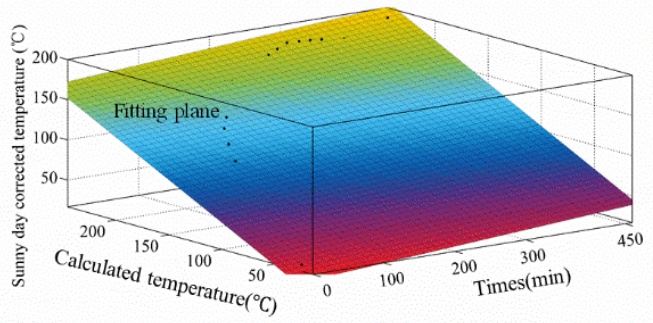

(b) Sunny day

Fig. 10. Semi-empirical relationship between corrected temperature and actual temperature. 
When the temperature of the heat source is determined, the calculated temperatures at different time can be obtained by fitting Eqs. (6) and (7) of the numerical model. Based on the temperature correction model, the average temperature in the heat storage tank in different weather conditions can be calculated, as shown in Fig. 11. Therefore, the corresponding mass fraction of liquid phase is corrected according to the temperature correction result according to Eqs. (8) and (9).

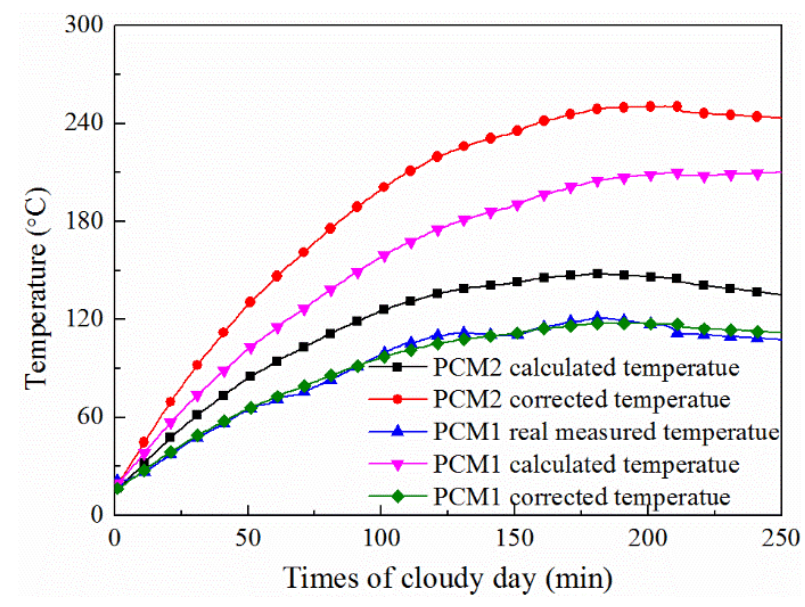

(a) Cloudy day

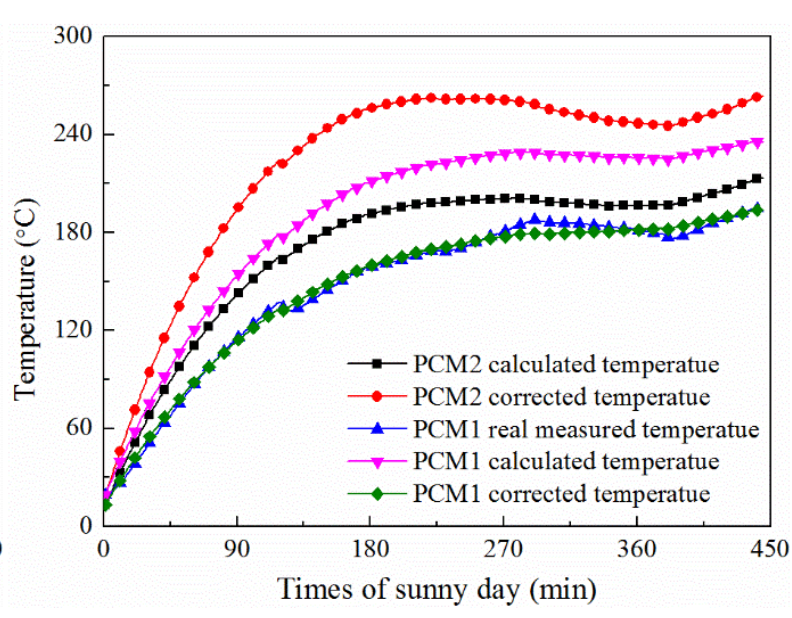

(b) Sunny day

Fig. 11. Calculated temperature, corrected temperature and the measured temperature results of the heat storage material.

As can be seen from Fig. 11, the calculated temperatures of PCM1 and PCM2 are both higher, which is related to the ideal adiabatic conditions considered in the simulation process. The higher the temperature of the tank, the larger the numerical calculated deviation. It can be seen that the corrected value of the PCM1 average temperature is almost exactly consistent with the measured results. In both sunny and cloudy days, the correction range is different due to the difference in ambient temperature and wind speed. The corrected temperature value is a temperature basis for calculating the subsequent heat transfer power and the stored heat amount.

\subsection{Heat transfer rate and energy storage calculation based on the empirical model}

According to the above-mentioned temperature correction model and the relationship among the mass fraction of liquid phase and the heat source temperature and the melting duration, the real-time heat transfer power in different weather conditions is depicted in Fig. 12. 


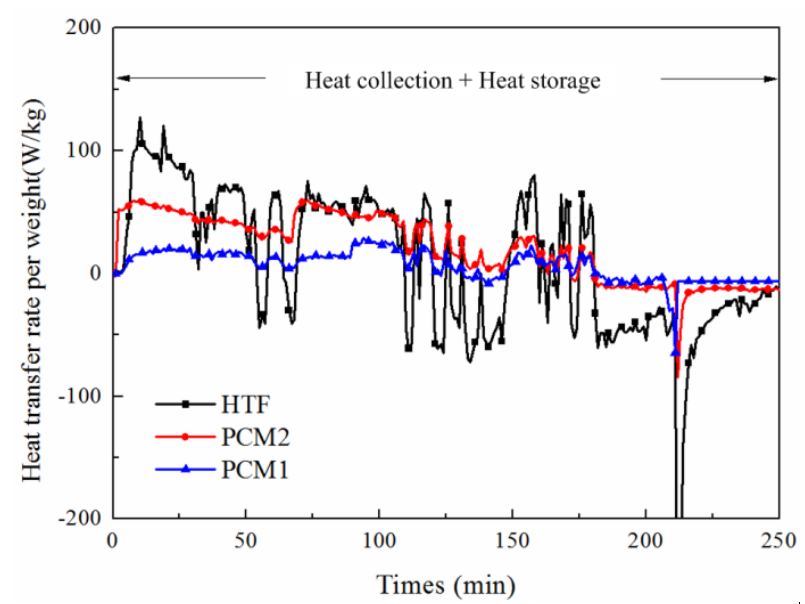

(a) Cloudy day

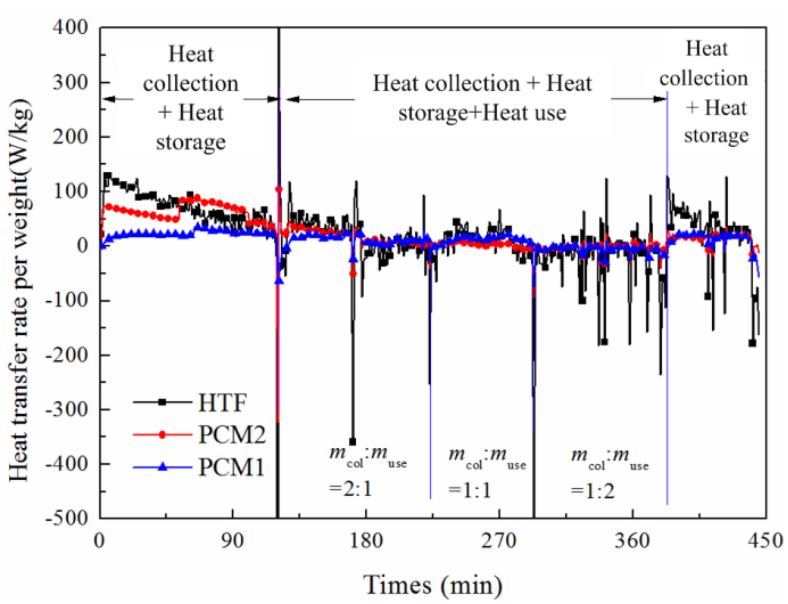

(b) Sunny day

Fig. 12. Real-time heat transfer rate of unit mass heat storage material.

In Fig. 12 the instantaneous heat transfer power of the HTF heat transfer in the cloudy weather presents sharp fluctuations with the influence of the external solar radiation. In sunny days, the instantaneous power of the HTF changes with the operation mode switching. The power curve bounce between the positive and negative values indicates the switchover between the heat storage and heat release conditions. In contrast, the two PCMs perform smoothly, and in different weather conditions the heat transfer rate of PCM2 is larger than that of PCM1 during the heat storage. When the heat is utilized, the heat release power happens to coincide with the heat storage rate, and the heat transfer rate of the PCMs is nearly zero in a short-time balanced state. The curve of HTF fluctuates around zero. Fig. 13 depicts the total heat output per unit mass of the HTF, PCM1 and PCM2.

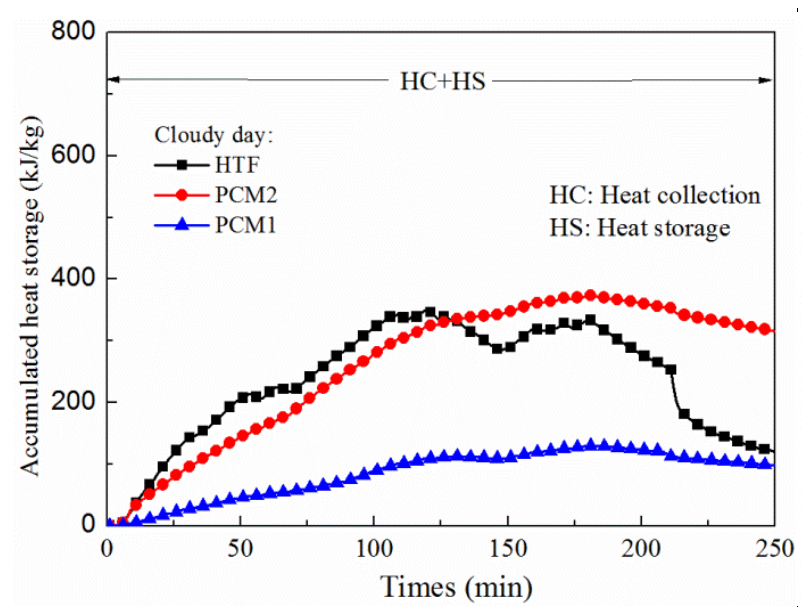

(a) Cloudy day

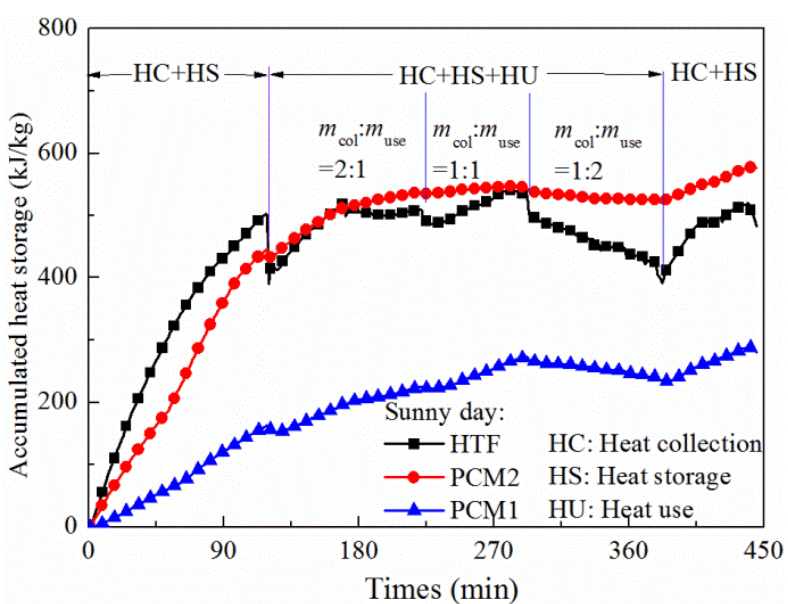

(b) Sunny day

Fig. 13. Cumulative heat storage capacity of unit mass heat storage material. 
As can be seen in Fig. 13, the cumulative heat transfer curves of the HTF, PCM1 and PCM2 in the two weather conditions change with the solar radiation and heat utilization. In general, the heat stored by HTF is higher at the beginning and is overtaken by PCM2 at a certain moment. PCM2 can store the most heat throughout the day while the heat stored by PCM1 is the least. This is because PCM1 has smaller thermal conductivity and higher phase transition temperature. In cloudy days, PCM2 overtakes the others when the heat collection process reaches approximately 131 minutes; in sunny days it happens beyond 120 minutes. This is due to a sharp decrease of the solar radiation during this period.

In addition, due to cloud and wind factors, even if only the heat collection and heat storage modes are used, the heat release of HTF is still carried out in the form of external heat loss. This alternation of heat storage and heat release is consistent with the fluctuation of solar radiation, and it also maintains the same trend as the temperature fluctuation of the heat transfer oil. However, the heat transfer curves of the PCMs do not fluctuate significantly. It is clear that the heat transfer is affected by the cooling process. This is more prominent when changing the environment in sunny days. For instance, in Fig. 13(b) the heat usage is suddenly activated at 120 min, leading a slight heat transfer decrease in PCM1 and PCM2. In the process of heat exchange with three different flow ratios from $120 \mathrm{~min}$ to $380 \mathrm{~min}$, there is a change in the heat storage capacity of the PCMs. During this period there are different rise or fall slopes in the curves of the PCMs. When the flow ratios are equal, the heat storage capacity of PCM1 still increases, while the heat storage of PCM2 remains constant. After $380 \mathrm{~min}$ in the heat utilization mode, the heat storage capacity of PCM1 slowly decreases, while the heat storage capacity of PCM2 remains constant. It can be seen from the comparison that PCM2 is less sensitive than PCM1 to external operating conditions and can maintain heat exchange at a relatively stable temperature. This is mainly because the process of heat storage and heat release occurs near the phase transition temperature of PCM2, while the PCM1 temperature is lower than the phase transition temperature in the exothermic phase. Additionally, in Fig. 9 the accumulated heat storage amount of PCM1 is much less than those of PCM2 and HTF, and the storage amount of PCM1 is not influenced significantly by the operation modes, so it is not suitable to use PCM1 in the solar thermal storage process.

Furthermore, the exergy analysis was conducted to compare the three kinds of heat storage from the second law of thermodynamics. The cumulative exergy storage capacity of unit mass heat storage material is shown in Fig. 14. 


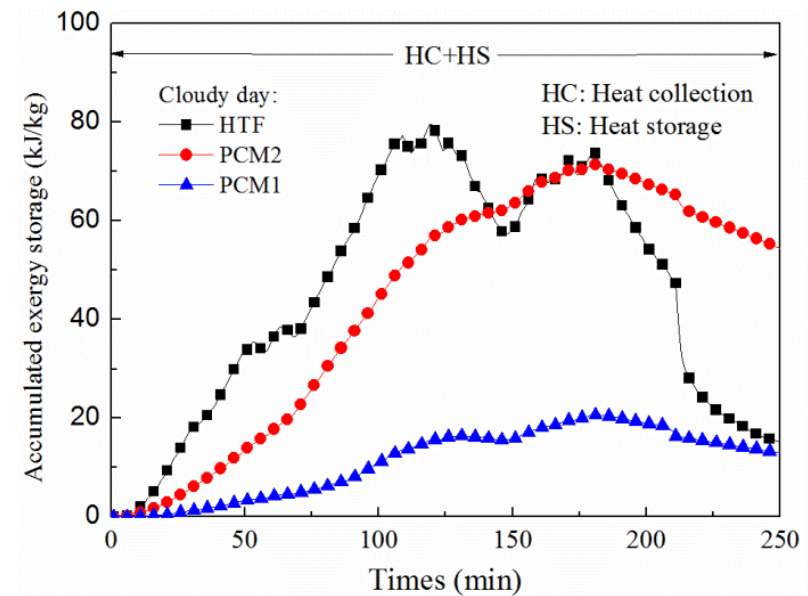

(a) Cloudy day

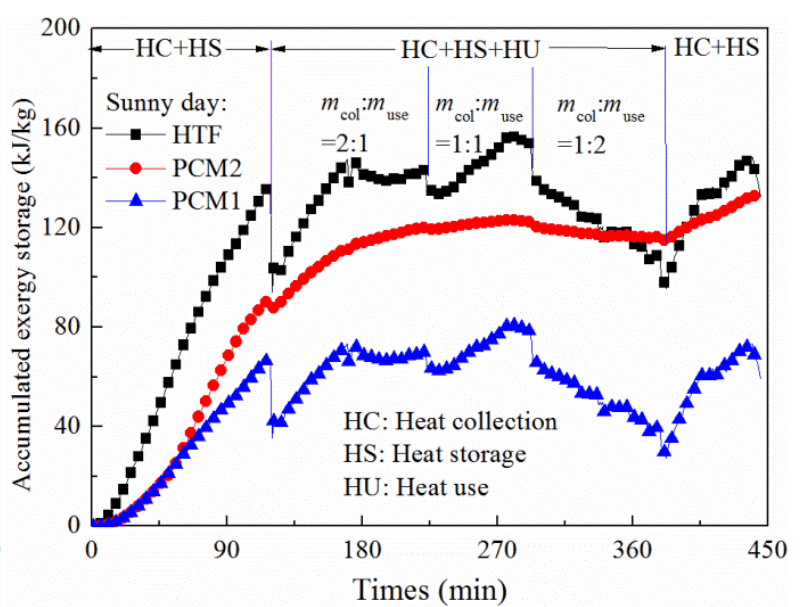

(b) Sunny day

Fig. 14. Cumulative exergy storage capacity.

It can be seen that the exergy storage of PCM1 is still the lowest, while HTF and PCM2 are better in the exergy storage amount. PCM2 also has a more stable exergy property, though the accumulative exergy amount is less than that of the HTF at the first stage. The comprehensive exergy performance of PCM2 is better than the other two. Especially, PCM1 indicates more instability in exergy amount than in the energy amount, but PCM2 does not present the similar condition. That is because PCM1 only works in sensible heat zone, while PCM2 works in the latent heat zone and attempts to keep a stable temperature under heat release condition.

\section{Conclusions}

In order to investigate the relationship between simulations and experimental results, this paper present a novel empirical heat transfer model of solar thermal storage process with PCMs. The proposed empirical heat transfer model is obtained by comparing the simulated and experimental results of the solar thermal storage. The main conclusions can be drawn as follows.

(1) The solar system performance can be evaluated by the proposed empirical heat transfer model under sunny and cloudy weather conditions. This newly proposed model includes corrected empirical formulas of PCM temperature and mass fraction of liquid phase, and hence, is able to theoretically simulate the solar thermal storage process with high consistence to the experimental results.

(2) During solar irradiation variations, the temperature of the latent heat storage tank is much more stable than that of the sensible heat storage tank, and the heat transfer power and heat storage amount of PCM1 per unit mass are less than that of the heat transfer oil. However, the heat transfer power and total heat storage amount of PCM2 may exceed those of the heat transfer oil at a certain moment. Regardless of 
the thermal instability of the heat transfer oil, the total heat storage capacity can be changed by the quantity of the heat storage material. These analysis results can provide a theoretical basis to select PCMs in the solar energy utilization process and to determine the amount of the PCMs.

(3) The heat utilization process under sunny and cloudy weather conditions can be regarded as the fluctuation of the solar radiation intensity. There is a critical time or critical temperature under different weather conditions for switching the operation mode of the heat storage to obtain better energy storage performance; that is, under the conditions of low temperature, low solar radiation intensity, and short-time heat storage conditions, the system may prefer to run the sensible heat storage rather than the latent heat storage, and vice versa. This finding can provide important theoretical reference for heat transfer analysis in solar energy storage process.

This work establishes a data-driven empirical heat transfer model for two typical weathers in a certain area, which provides a theoretical and experimental basis for the thermal utilization of solar energy systems. However, a complete model of the typical weather experience heat transfer model has not yet been established. At the same time, a complete heat transfer system is integrated with the solar collection and heat storage process. This is one of the main tasks of the future work. In addition, we can see from the conclusion that the weather has a great influence on heat transfer, which means that the performance matching among the heat storage unit, the heat collection unit, and the heat use unit will also become one issue for maximizing the heat utilization efficiency of the solar energy system.

\section{Appendix}

\section{A. Numerical simulation model and boundary condition setting}

A simulation model about the simplified real object was established. In this numerical model the decay effect of HTF temperature can be neglected because the length of the LHTES tank is $500 \mathrm{~mm}$. Fourteen fins evenly installed along the axial direction of the LHTES tank. Considering that the LHTES tank is geometrically identical along its axial direction, the physical model can be simplified as shown in Fig. 15. A half part between the two mean lines of adjacent fins along axial direction and merely the right side was selected as the calculation domain, that is, including a half of a fin and a half of the two fins spacing. Then a commercial software ICEM was adopted to mesh it, and the grid independence was verified. The model was divided into 104 thousand, 186 thousand, 487 thousand and 639 thousand grids. In order to saving calculating time, he verification only calculated the temperature in $5 \mathrm{~min}$, and the results were shown in Fig. 5. From the figure, the maximum error with more than 186 thousand grid quantity is $1.1 \%$, and the error with 104 thousand grids is larger than 186 thousand. Both considering the calculating speed and 
accuracy, 186 thousand hexahedral grids are selected for simulation in this paper. The detailed grid structure and grid quality analysis are also as shown in Fig. 16.

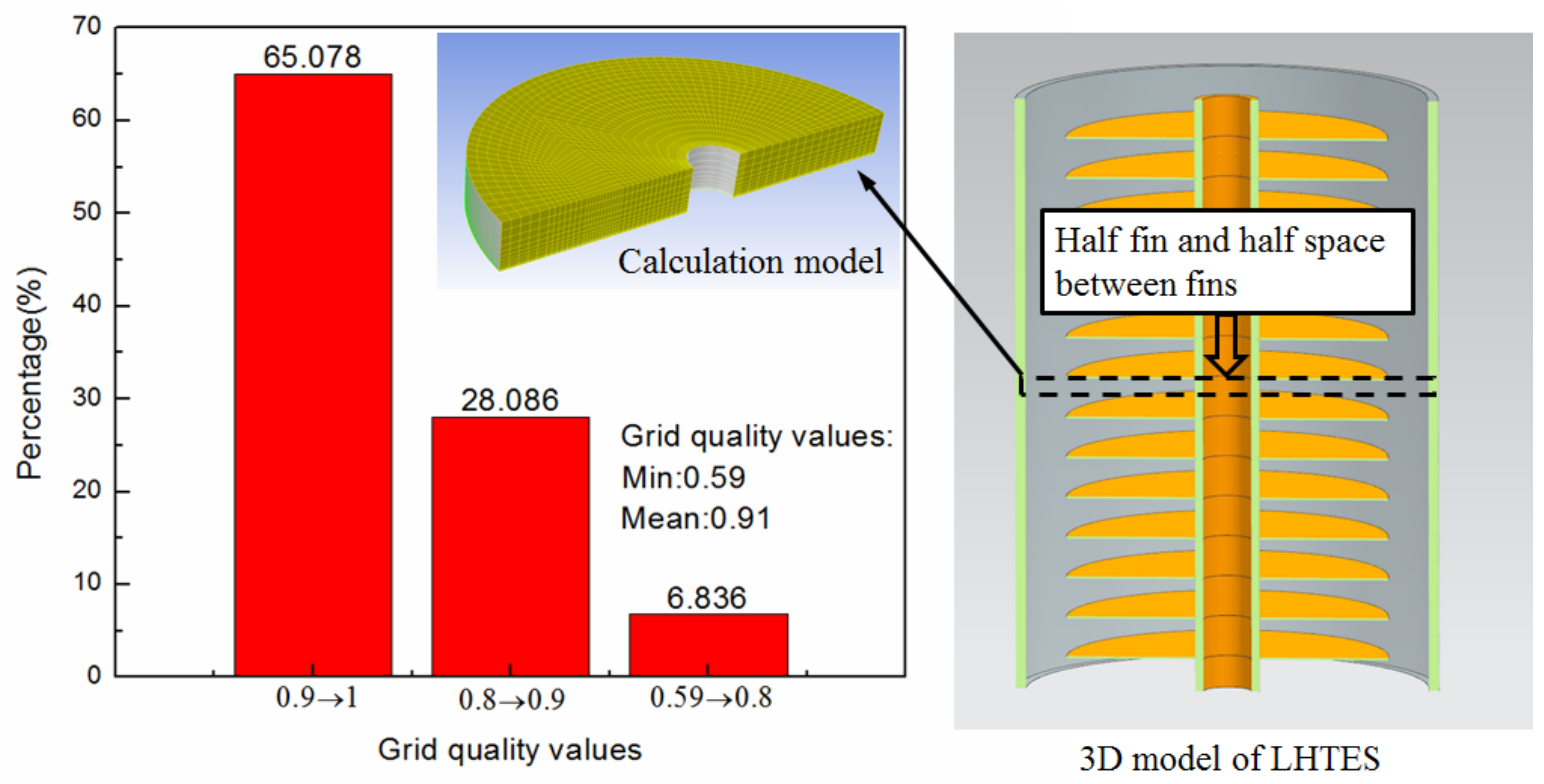

Fig. 15. 3D model of LHTES and grid quality analysis of calculation model

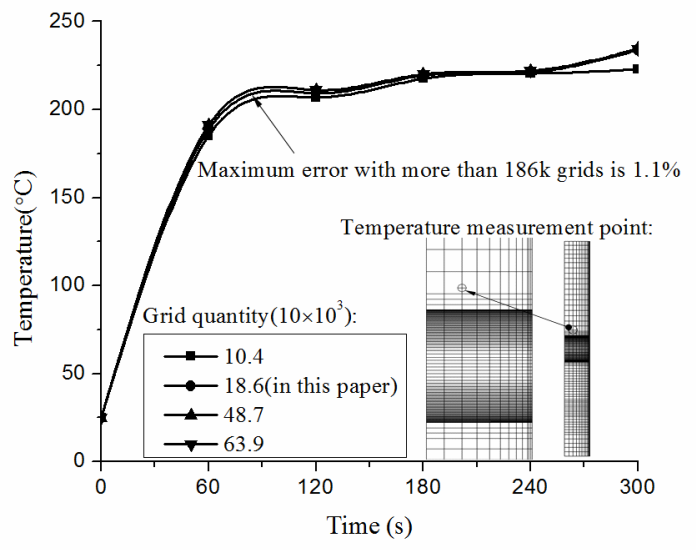

Fig. 16. Verification of grid independence

To simplify the simulation, some assumptions are made as follows: (1) The liquid phase molten salt is incompressible Newtonian fluid and is applicable for the Boussinesq hypothesis. The natural convection happens under the condition of laminar flow. (2) The fluid surface tension and the volume change of molten salt during the phase transition can be negligible. (3) Assume the temperature of inner wall is equal to that of the HTF, for the heat transfer resistance of HTF and the tube wall is much smaller than that of the molten salt. The boundary conditions of the PCMs melting processes in Fig. 15 are identical boundaries in side 
surfaces and adiabatic boundary in outer contour. Coupling boundary is used on the surface between the PCM and heat tubes and fins, where continuous temperature and heat flux are adopted. The initial melting temperature is $25^{\circ} \mathrm{C}$, the temperatures of the heat tubes are set to $270{ }^{\circ} \mathrm{C}, 260{ }^{\circ} \mathrm{C}$ and $250{ }^{\circ} \mathrm{C}$, respectively. The simulation results did sufficient comparison with the experimental results in the reference, in which the conclusion has obtained that the accuracy of the melting process simulation is acceptable. To avoid duplication, this is not repeated here.

\section{B. Model correction discussions}

In Sections 3.2 and 4.3, the equations for calculating the PCM average temperature for latent heat storage processes and the temperature correction model are established, respectively. It is worth mentioning that the related parameters are greatly influenced by environmental factors and the experimental platform. To explore the effect of correction model coefficient on the calculated average temperature under different environmental conditions, the adaptability of the correction model is discussed.

This paper attempted to correct the temperature of the cloudy sky by using a sunny correction model using Eq. (13); vise verse. Then the average coefficient values of the two correction models were used to correct the temperature of the numerical model. The new correction model is described in Eq. (14), whose coefficients are the average of those in Eqs. (12) and (13). The calculated and corrected temperatures are shown in Fig. 17.

$$
t_{\text {ave, corrected }}=1.6205-0.0966 \tau+0.689 t_{\text {calculated }}
$$

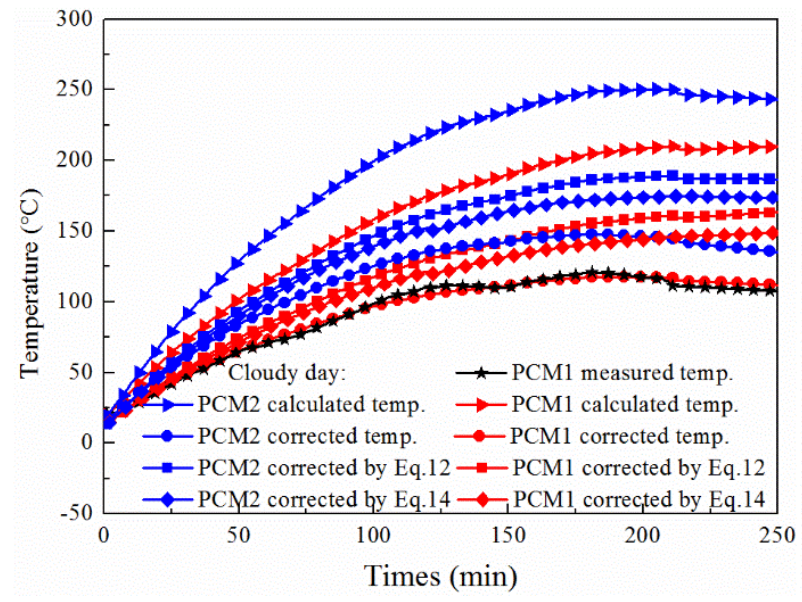

(a) Cloudy day

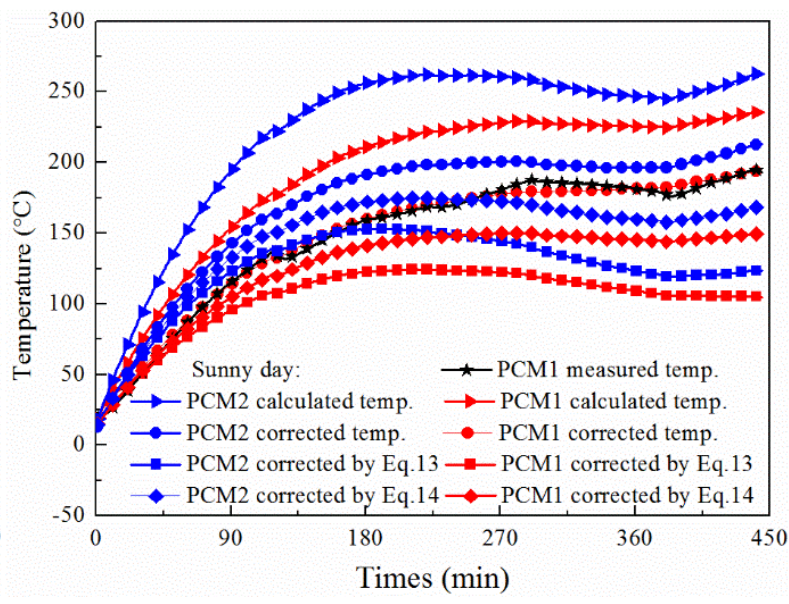

(b) Sunny day

Fig. 17. Results of corrected temperature under different correction coefficients. 
As can be seen from Fig. 17, the coefficients in Eq. (17) are inappropriate. An inappropriate model may cause a large deviation of the correction temperature. If the sunny day model is used to correct the temperature of cloudy days, the correction value is obviously larger. PCM1 has a positive deviation of $46.1 \%$ in the final state of 450 minutes, and PCM2 has a maximum positive deviation of $38.2 \%$. Conversely, using a cloudy model to correct the temperature of sunny days, the correction value is significantly smaller, PCM1 has a maximum negative deviation of $45.9 \%$ in the $450 \mathrm{~min}$, and PCM2 has a maximum negative deviation of $42.1 \%$. These large deviations are proven that the correction is high related to the weather, and a generic correction model cannot be obtained. In the initial stage of heat storage, such as within the first 30 minutes, the temperature results obtained by different correction models are close, but gradually increase with time and heat source temperature. The reason is probably that the heat loss in the LHTES tank is greater in sunny days than that in cloudy days. The higher the overall temperature is, the higher the heat loss is. More importantly, the temperature corrected using the average coefficient model still has a deviation of about $20 \%$ of the correction value of the appropriate model at a high temperature. Therefore, when considering the correction model, it should correspond to the weather conditions and the temperature increasing process of the phase change material itself. When the weather conditions are similar and the operating conditions are the same, the same correction model can be used for temperature correction. Therefore, it can be deduced that though the empirical model is universal, the coefficient should be optimized according to specific weather and environmental condition. Thus the proposed approach still needs to improve in future.

\section{Acknowledge}

This project is supported by the NSFC (no. U1137605), the Collaborative Innovation Center of Research and Development of Renewable Energy in the southwest area in China (no. 05300205020516009) and the Co-establishing China-Laos Joint Lab for Renewable Energy (no. 2015DFA60120).

\section{References}

[1] Silva R, Pérez M, Fernández-Garcia A. Modeling and co-simulation of a parabolic trough solar plant for industrial process heat. Applied Energy, 2013, 106(106): 287-300.

[2] China national bureau of statistics. 2017 China statistical almanac, energy. http://www.stats.gov.cn/tj sj/ndsj/2017/indexch.htm

[3] Kıyan M, Bingöl E, Melikoğlu M, et al. Modelling and simulation of a hybrid solar heating system 
for greenhouse applications using Matlab/Simulink. Energy Conversion \& Management, 2013, 72(8): $147-155$.

[4] Vignarooban K, Xu X, Arvay A, et al. Heat transfer fluids for concentrating solar power systems - A review. Applied Energy, 2015, 146: 383-396.

[5] Wang F, Cheng Z, Tan J, et al. Progress in concentrated solar power technology with parabolic trough collector system: A comprehensive review. Renewable \& Sustainable Energy Reviews, 2017, 79: 1314-1328.

[6] Duffie J A, Beckman W A. Chapter16: Solar Industrial Process Heat. Solar Engineering of Thermal Processes. John Wiley \& Sons, Inc. 2013: 604-620.

[7] Farjana S H, Huda N, Mahmud M A P, et al. Solar process heat in industrial systems - A global review[J]. Renewable \& Sustainable Energy Reviews, 2018, 82: 2270-2286.

[8] Tian Y, Zhao C Y. A review of solar collectors and thermal energy storage in solar thermal applications. Applied Energy, 2013, 104(4): 538-553.

[9] Gil A, Medrano M, Martorell I, et al. State of the art on high temperature thermal energy storage for power generation. Part 1 - Concepts, materials and modellization. Renewable \& Sustainable Energy Reviews, 2010, 14(1): 56-72.

[10] Lane G A. Solar heat storage: latent heat materials. Vol.1 Boca Raton, FL: CRC Press, Inc., 1983.

[11] Zhang S, Zhang L, Yang X, et al. Experimental Investigation of a Spiral Tube Embedded Latent Thermal Energy Storage Tank Using Paraffin as PCM. Energy Procedia, 2017, 105: 4543-4548.

[12] Li B, Zhai X, Cheng X. Experimental and numerical investigation of a solar collector/storage system with composite phase change materials. Solar Energy, 2018, 164: 65-76.

[13] Fan L W, Zhu Z Q, Xiao S L, et al. An experimental and numerical investigation of constrained melting heat transfer of a phase change material in a circumferentially finned spherical capsule for thermal energy storage. Applied Thermal Engineering, 2016, 100: 1063-1075.

[14] Feng S, Cheng Y, An element decomposition method for heat transfer analysis. International Journal of Heat and Mass Transfer, 2018, 123: 437-444.

[15] Feng S, An accurate and efficient algorithm for the simulation of fatigue crack growth based on XFE M and combined approximations. Applied Mathematical Modelling, 2018, 55: 600-615.

[16] Feng S, Cui X, Li A, Fast and efficient analysis of transient nonlinear heat conduction problems usin g combined approximations (CA) method. International Journal of Heat and Mass Transfer, 2016, 97 : 638-644.

[17] Yadav A S, Bhagoria J L. Heat transfer and fluid flow analysis of solar air heater: A review of CFD approach. Renewable \& Sustainable Energy Reviews, 2013, 23(23): 60-79.

[18] Yang X, Lu Z, Bai Q, et al. Thermal performance of a shell-and-tube latent heat thermal energy storage 
unit: Role of annular fins. Applied energy, 2017, 202: 558-570.

[19] Pizzolato A, Sharma A, Maute K, et al. Design of effective fins for fast PCM melting and solidification in shell-and-tube latent heat thermal energy storage through topology optimization. Applied Energy, 2017, 208: 210-227.

[20] Fornarelli F, Camporeale S M, Fortunato B, et al. CFD analysis of melting process in a shell-and-tube latent heat storage for concentrated solar power plants. Applied energy, 2016, 164: 711-722.

[21] Dutil Y, Rousse D R, Salah N B, et al. A review on phase-change materials: Mathematical modeling and simulations. Renewable \& Sustainable Energy Reviews, 2011, 15(1): 112-130.

[22] Augspurger M, Udaykumar H S. Transient multi-day simulations of thermal storage and heat extraction for a finned solar thermal storage device. Solar Energy, 2017, 151: 48-60.

[23] Kastner O, Norden B, Klapperer S, et al. Thermal solar energy storage in Jurassic aquifers in Northeastern Germany: A simulation study. Renewable energy, 2017, 104: 290-306.

[24] Bie Y, Li M, Malekian R, et al. Effect of Phase Transition Temperature and Thermal Conductivity on the Performance of Latent Heat Storage System. Applied Thermal Engineering, 2018, 135: 218-227.

[25] Youssef W, Ge Y T, Tassou S A. CFD modelling development and experimental validation of a phase change material (PCM) heat exchanger with spiral-wired tubes. Energy Conversion \& Management, 2018, 157: 498-510.

[26] Almsater S, AlemuAlemu, Saman W, et al. Development and experimental validation of a CFD model for PCM in a vertical triplex tube heat exchanger. Applied Thermal Engineering, 2017,116: 344-354.

[27] Bayón R, Rojas E, Valenzuela L, et al. Analysis of the experimental behaviour of a 100kW latent heat storage system for direct steam generation in solar thermal power plants. Applied Thermal Engineering, 2010, 30(17): 2643-2651.

[28] Al-Jethelah M, Tasnim S H, Mahmud S, et al. Nano-PCM filled energy storage system for solarthermal applications. Renewable Energy, 2018.126: 137-155.

[29] Lu S, Zhao Y, Fang K, et al. Establishment and experimental verification of TRNSYS model for PCM floor coupled with solar water heating system. Energy \& Buildings, 2017, 140: 245-260.

[30] Yuan F, Li M J, Ma Z, et al. Experimental study on thermal performance of high-temperature molten salt cascaded latent heat thermal energy storage system. International Journal of Heat \& Mass Transfer, 2018, 118: 997-1011.

[31] Kabeel A E, Khalil A, Shalaby S M, et al. Experimental investigation of thermal performance of flat and v-corrugated plate solar air heaters with and without PCM as thermal energy storage. Energy Conversion \& Management, 2016, 113: 264-272.

[32] Xue H S. Experimental investigation of a domestic solar water heater with solar collector coupled phase-change energy storage. Renewable Energy, 2016, 86: 257-261. 
[33] Motahar S, Alemrajabi A A, Khodabandeh R. Experimental study on solidification process of a phase change material containing $\mathrm{TiO}_{2}$ nanoparticles for thermal energy storage. Energy conversion and management, 2017, 138: 162-170.

[34] Agyenim F., Hewitt N, Eames P, Smyth M. A review of materials, heat transfer and phase change problem formulation for latent heat thermal energy storage systems (LHTESS). Renewable and sustainable energy reviews 2010, 14: 615-628.

[35] Pandey A, Hossain M, Tyagi V, Rahim N, Jeyraj A, Selvaraj L, Ahmet S. Novel approaches and recent developments on potential applications of phase change materials in solar energy. Renewable and Sustainable Energy Reviews 2018, 82: 281-323.

[36] Sivasamy P, Devaraju A, Harikrishnan S. Review on Heat Transfer Enhancement of Phase Change Materials (PCMs). Materials Today, 2018, 6: 14423-14431.

[37] Peng Q, Ding J, Wei X, et al. The preparation and properties of multi-component molten salts. Applied Energy, 2010, 87(9): 2812-2817. 